\title{
A systematic analysis of distressing near-death experience accounts
}

\section{Helena Cassol, Charlotte Martial, Jitka Annen, Géraldine Martens, Vanessa Charland-Verville, Steve Majerus \& Steven Laureys}

To cite this article: Helena Cassol, Charlotte Martial, Jitka Annen, Géraldine Martens, Vanessa Charland-Verville, Steve Majerus \& Steven Laureys (2019): A systematic analysis of distressing near-death experience accounts, Memory, DOI: 10.1080/09658211.2019.1626438

To link to this article: https://doi.org/10.1080/09658211.2019.1626438

曲 Published online: 12 Jun 2019.

Submit your article to this journal $\asymp$

Џ Article views: 25

View Crossmark data \lceil 


\title{
A systematic analysis of distressing near-death experience accounts
}

\author{
Helena Cassol ${ }^{a, b}$, Charlotte Martial ${ }^{a, b}$, Jitka Annen ${ }^{a, b}$, Géraldine Martens ${ }^{a, b}$, Vanessa Charland-Verville ${ }^{a, b}$, \\ Steve Majerus ${ }^{c}$ and Steven Laureys ${ }^{a, b}$ \\ ${ }^{\mathrm{a}}$ GIGA Consciousness, GIGA Research Center University of Liège, Liège, Belgium; ${ }^{\mathrm{b}}$ Coma Science Group, University Hospital of Liège, Liège, \\ Belgium; 'Psychology and Neuroscience of Cognition Research Unit, University of Liege, Liège, Belgium
}

\begin{abstract}
Near-death experiences (NDEs) are usually associated with positive affect, however, a small proportion are considered distressing. We aimed to look into the proportion of distressing NDEs in a sample of NDE narratives, categorise distressing narratives according to Greyson and Bush's classification (inverse, void or hellish), and compare distressing and "classical" NDEs. Participants wrote down their experience, completed the Memory Characteristics Questionnaire (assessing the phenomenology of memories) and the Greyson scale (characterising content of NDEs). The proportion of suicidal attempts, content and intensity of distressing and classical NDEs were compared using frequentist and Bayesian statistics. Distressing NDEs represent $14 \%$ of our sample $(n=123)$. We identified 8 inverse, 8 hellish and 1 void accounts. The proportion of suicide survivors is higher in distressing NDEs as compared to classical ones. Finally, memories of distressing NDEs appear as phenomenologically detailed as classical ones. Distressing NDEs deserve careful consideration to ensure their integration into experiencers' identity.
\end{abstract}

\section{ARTICLE HISTORY}

Received 27 March 2019

Accepted 29 May 2019

\section{KEYWORDS}

Near-death experiences; distressing near-death experiences; Memory Characteristics Questionnaire; phenomenology
Having the sensation of being out of the physical body, seeing a bright light or meeting a deceased relative are features that one can experience when being close to death (Greyson, 1983). Near-death experiences (NDEs) typically occur during non-ordinary mental expressions and following life-threatening situations (Facco, Agrillo, \& Greyson, 2015; Hou, Huang, Prakash, \& Chaudhury, 2013; Van Lommel, Van Wees, Meyers, \& Elfferich, 2001). They have been reported in 6-23\% of cardiac arrest survivors (Parnia et al., 2014; Parnia, Waller, Yeates, \& Fenwick, 2001; Schwaninger, Eisenberg, Kenneth, \& Weiss, 2002; Van Lommel et al., 2001) and have generally been associated with positive emotions, such as peacefulness or a sense of harmony with the universe (Charland-Verville et al., 2014). Moreover, the memory of these experiences seems to be vivid and highly detailed (Martial et al., 2017; Moore \& Greyson, 2017; Palmieri et al., 2014; Thonnard et al., 2013) as assessed by the Memory Characteristics Questionnaire (MCQ) (Johnson, Foley, Suengas, \& Raye, 1988). Several authors have already highlighted the powerful changes triggered by NDEs on the lives of people who have lived these experiences (so-called NDErs), such as a reduced fear of death or being less materialistic (Groth-Marnat \& Summers, 1998; Van Lommel et al., 2001).

Although generally described as pleasant and leading to positive changes, a small proportion of NDEs has been depicted as negative and sometimes "hellish". To date, only a few studies have addressed these distressing experiences and we do not precisely know their causes and potential consequences (Bush, 2002; Greyson \& Bush, 1992). Moreover, their prevalence seems to vary widely. For example, most early studies on NDEs only depicted positive emotions (Ring, 1980, 1984). Lindley and collaborators (Lindley, Bryan, \& Conley, 1981) however published an interdisciplinary study in which they identified 55 NDErs, of which eleven reported "negative" experiences (including one "hellish"). More recently, a study by our group (Charland-Verville et al., 2014) pointed out that $10 \%$ of the sample did not describe positive emotions. Overall, we should note that the heterogeneous set of tools used to identify negative NDEs might strongly influence the data. Moreover, some of these numbers may underestimate the actual percentage. Indeed, although NDEs seem to come out of the taboo atmosphere, some NDErs might still feel reluctant to share them. This could be even more the case when these experiences are perceived as distressing or upsetting, as memory retrieval may be painful and as people might feel stigmatised (Greyson \& Bush, 1992). Besides, as stated by Greyson and Bush (1992), current widely used NDE questionnaires, such as the Greyson NDE scale (Greyson, 1983) and the Weighted Core Experience Index (WCEl) (Ring, 1980), only focus on positive emotions and might fail in identifying these distressing experiences.

CONTACT Helena Cassol hcassol@uliege.be E GIGA Consciousness, GIGA Research Center University of Liège, Avenue de I'hôpital 1, 4000 Liège (Sart-Tilman), Belgium

This article has been republished with minor changes. These changes do not impact the academic content of the article.

(c) 2019 Informa UK Limited, trading as Taylor \& Francis Group 
Only a small number of empirical studies have addressed distressing NDEs in-depth. In addition, most of them have focused on single cases, thereby affecting the generalisability of their observations (Bonenfant, 2001; Irwin \& Bramwell, 1988). One noteworthy finding is the existence of experiences beginning the same way as classical NDEs, but that suddenly become negatively toned. To learn more about the content of distressing NDEs, Greyson and Bush (1992) looked closely into the content of 50 self-reported accounts and identified three subcategories of frightening experiences. Firstly, those containing features similar to classical NDEs, with the exception that the NDEr considers the whole experience as unpleasant. According to these authors, it is the most frequently reported type. These distressing NDEs had already been described by Ring (1984) who called them "inverse", with reference to their resemblance with classical NDEs. Secondly, those in which the NDEr is in an isolated and eternal void (i.e. "void" NDEs). Finally, the rarest type, "hellish", is described as experiences of visiting hell-like regions and encountering demonic beings. Later, Rommer (2000) suggested a fourth type in which NDErs are heavily disturbed by a life review. This category has however been classified by Bush (2002) as a subset of the "hellish" experiences. Although there has been an indication about the relative size of the different categories, the occurrence of these three subcategories in the reported sample has not been supplied. In addition, even though this pioneer article illustrates distressing experiences by providing numerous verbatim accounts, to date, no study has performed a rigorous analysis of the phenomenology of these subtypes of NDEs by multiple coders.

Regarding potential causes, the unpredictable aspect of NDEs makes it difficult to identify the psychological and physiological status before a distressing experience (Greyson \& Bush, 1992). The literature has often suggested a relationship between the negative emotional context of suicides and the nature of the resulting NDE (Greyson \& Stevenson, 1980; Ring \& Franklin, 1982). However, even if this relationship remains largely under-explored, Ring and Franklin (1982) have reported that suicide-related NDEs are not different from NDEs in general. Overall, the few available scientific data and the potentially longlasting emotional trauma triggered by frightening NDEs advocate for further rigorous studies (Bush, 2002).

In this respect, we aim to (1) look for the proportion of "distressing" NDEs in a relatively large sample of selfreported NDE narratives; (2) classify the distressing narratives by multiple assessors, in order to have a precise estimate of the occurrence of the three subtypes of "negative" NDEs; and (3) compare memories of distressing and "classical" (i.e. experiences comprising typical features and not perceived as negative) NDEs on the basis of their content, intensity, phenomenological details and proportions of suicidal attempts.

\section{Materials and methods}

\section{Participants and procedure}

\section{Participants}

Participants were initially recruited following calls for NDE testimonies via the websites, the appearances in local media and the publications of the Coma Science Group (GIGA-Consciousness, University and University Hospital of Liège, Belgium) as well as the International Association for Near-Death Studies (IANDS France and Flanders). They were then mailed questionnaires including items relating to socio-demographic (gender, age at NDE, age at interview) and clinical (time since NDE, presence of a loss of consciousness exceeding one hour) characteristics. Participants, who were not aware of the specific purpose of the research, were subsequently invited to freely write down a detailed description of the experience on blank sheets of paper, with no restriction regarding text size. Lastly, they were asked to complete the Greyson NDE scale (Greyson, 1983). This validated 16-item questionnaire enables the quantification of the intensity of a NDE (i.e. the total score ranges from 0 to 32) and the identification of "true" NDEs with a total cut-off score of 7 (Greyson, 1983; Lange, Greyson, \& Houran, 2004). The Greyson NDE scale assesses the presence and content of 16 features that fall into four subscales (i.e. affective, cognitive, paranormal and transcendental components). For each item, scores are arranged on an ordinal scale ranging from 0 to 2 (i.e. $0=$ "not present" $1=$ "mildly or ambiguously present", and 2 = "definitively present"). We only included experiences equal or above the cut-off score of 7 that occurred following a severe brain injury accompanied by a period of coma (loss of consciousness exceeding one hour) and a hospitalisation in an intensive care unit. Additionally, participants filled out a short version (D'Argembeau \& Van der Linden, 2008) of the Memory Characteristics Questionnaire (MCQ) (Johnson et al., 1988). It includes 16 items (each rated on a 1-7 points Likert scale) assessing the following categories of memory characteristics: memory clarity, sensory details, self-referential and emotional information, reactivation frequency, and confidence in the memory.

The study was carried out in accordance with the recommendations of the ethics committee of the Faculty of Medicine of the University of Liège. The protocol was approved by the ethics committee of the Faculty of Medicine of the University of Liège. All participants completed a written informed consent in accordance with the Declaration of Helsinki.

\section{Classification of distressing experiences}

The first step consisted in identifying distressing NDE narratives. To that end, we evaluated responses at item 14 of the short version of the MCQ (i.e. 'When the event happened, my emotions were: $-3=$ "very negative", 0 $=$ "neutral", $+3=$ "very positive" $)$ and selected the 
narratives that were rated between -1 and -3 . All written narratives were therefore divided into two main emotionsrelated groups (i.e. distressing NDEs and "classical" NDEs). The dataset, including distressing narratives that had to be classified into three subtypes (i.e. inverse, void and hellish), was created and composed of 5 Dutch and 12 French narratives. Their average length was of 975 words per account (ranging from 206 to 4795). A detailed description of the subtypes (Greyson \& Bush, 1992) was provided to coders (i.e. two Dutch speakers and two French speakers). Each account was then independently read by the two coders who perfectly mastered the language in which it was written. NDE features corresponding to each of the three subtypes were highlighted in different colours. The pre-determined features corresponding to each type of distressing NDE can be found in Table 1. The number of observed agreements was 5/5 for Dutch narratives and 11/12 (92\%) for French narratives. Interrater reliability was assessed using a Cohen's kappa coefficient. The closer the value to 1 , the better the concordance is between coders (Landis \& Koch, 1977). We obtained a Cohen's kappa coefficient of 1 ("perfect" agreement) for Dutch narratives and of 0.855 (95\% confidence intervals 0.583-1; "very good" agreement) for French narratives. Discrepancy was discussed in order to reach a final unanimous categorisation.

\section{Statistical analysis}

We calculated the proportion (\%) of distressing NDEs by taking into account all the NDErs that had provided us with a written narrative and who had duly completed all questionnaires (i.e. Greyson NDE scale and MCQ) since the beginning of enrolment in 2010. NDErs who reported distressing NDEs were compared to NDErs who reported classical NDEs regarding demographical and clinical information. Differences between groups were assessed using Student's t-tests (for age at NDE, age at interview and time elapsed since NDE) and Fisher's exact tests (for aetiology and gender). Results were considered significant at an alpha of $0.05(p<0.05)$ and were expressed as mean \pm standard deviation (SD) for quantitative variables and as counts and proportions (\%) for the qualitative variables.
Regarding answers at questionnaires, Greyson NDE scale scores distributions being skewed and the answers at the MCQ being ordinal data measures, distressing and classical NDEs were compared using Mann Whitney $U$ tests and results were expressed as median (inter-quartile range). We corrected for multiple comparisons using a Bonferroni correction, setting the criterion for statistical significance at $p<0.0125$ for the Greyson NDE subscales scores and at $p<0.003$ for the 16 items of the MCQ. The item relating to the valence was included in our analysis to ensure a clear difference between the two emotionsrelated groups. As a second step, and in accordance with recent recommendations (Dienes, 2014), we conducted Bayesian Mann-Whitney tests in addition to frequentist inferential analyses. Indeed, unlike classical inference methods which can only provide evidence against the null hypothesis, Bayesian methods have the advantage of quantifying the evidence for and against it (Dienes, 2014). Regarding data interpretation, we considered a Bayes Factor (BF) of $<3$ as anecdotal evidence, between 3 and 10 as moderate evidence, between 10 and 30 as strong evidence, between 30 and 100 as very strong evidence, and higher than 100 as decisive evidence for the model tested relatively to the null or to another model (Lee \& Wagenmakers, 2014). BF $_{10}$ indicates Bayesian evidence for the presence of an effect relative to the null, and $\mathrm{BF}_{01}$ indicates evidence for the null. Data analyses were carried out using SPSS (Statistical Package for the Social Sciences, version 22.0, SPSS Inc., Chicago, IL, USA) and with the 0.9.0.1 version of the JASP software package for Bayesian analyses, using default settings for prior distributions.

\section{Results}

\section{Demographic data}

We received the testimonies from 506 participants since the beginning of the enrolment in 2010. Among these, 123 individuals met the criteria of an NDE (i.e. Greyson NDE scale cut-off $\geq 7$ ), had duly completed questionnaires and were included in our analyses, of which 17 were

Table 1. General description and features belonging to distressing near-death experiences subtypes.

\begin{tabular}{ll}
\hline Type & General description and features \\
\hline Inverse & $\begin{array}{c}\text { Narratives contain classical NDE features but the event is considered as unpleasant (Greyson \& Bush, 1992) Coders considered features described in } \\
\text { the two most used NDE scales (i.e. Greyson NDE scale and Weighted Core Experience Index - WCEI - scale (Greyson, 1983; Ring, 1980): (1) intense } \\
\text { feeling of joy, (2) peacefulness, (3) altered time perception, (4) accelerated thoughts, (5) vision of scenes belonging to one's past/life review, (6) } \\
\text { sensation of understanding everything (about oneself, others or the universe), (7) feeling of harmony with the universe, (8) vision of a very bright } \\
\text { light, (9) communication with a light, (10) vision of/moving through a tunnel, (11) more vivid senses than usual, (12) being aware of things } \\
\text { happening elsewhere, (13) visions of the future, (14) out-of-body experience, (15) entering a non-terrestrial world, (16) encounter with a mystical } \\
\text { being/voice, (17) vision of dead or religious spirits, (18) coming to a border/point of no return, (19) awareness of being dead, (20) observation of } \\
\text { colours, (21) observation of a celestial landscape, and (22) darkness. } \\
\text { Narratives might contain features belonging to the classical type but in a smaller amount. Void accounts should also involve (1) an acute awareness } \\
\text { of nonexistence, (2) the sensation of being completely alone forever in an absolute void, and/or (3) receiving a convincing message saying that } \\
\text { the real world never existed (Greyson \& Bush, 1992). } \\
\text { Narratives might also contain features belonging to the prototypical type and to the void type. This subtype should also encompass hellish imagery } \\
\text { and sounds such as 1) the vision of an ugly or foreboding landscape, 2) the presence of demonic beings, 3) hearing loud and/or annoying noises, } \\
\text { 4) seeing frightening animals and/or 5) encountering other beings in extreme distress (Greyson \& Bush, 1992). }\end{array}$ \\
Hellish
\end{tabular}


Table 2. Demographical information of NDErs who experienced a distressing NDE vs. a classical NDE.

\begin{tabular}{|c|c|c|c|c|c|}
\hline & $\begin{array}{l}\text { Distressing NDEs } \\
\quad(n=17)\end{array}$ & $\begin{array}{c}\text { Classical NDEs } \\
\quad(n=106)\end{array}$ & $p$-Value & & \\
\hline $\begin{array}{l}\text { Gender - female } \\
\quad N(\%)\end{array}$ & $\begin{array}{c}12 \\
(71)\end{array}$ & $\begin{array}{c}61 \\
(58)\end{array}$ & 0.43 & & \\
\hline \multirow[t]{2}{*}{ Aetiology - suicide attempt $N(\%)$} & $\begin{array}{c}4 \\
(24) \\
\end{array}$ & $\begin{array}{c}1 \\
(1)\end{array}$ & $<0.001^{*}$ & & \\
\hline & & & $t$ & $p$-Value & $\begin{array}{c}\mathrm{G}_{\text {Hedges }} \\
\left(\mathrm{Cl}_{95}\right)\end{array}$ \\
\hline $\begin{array}{l}\text { Age at NDE } \\
\text { Mean in years }( \pm S D)\end{array}$ & $\begin{array}{c}34 \\
(17)\end{array}$ & $\begin{array}{c}32 \\
(17)\end{array}$ & 0.36 & 0.723 & $\begin{array}{l}-0.118 \\
(-0.63-0.395)\end{array}$ \\
\hline $\begin{array}{l}\text { Age at interview } \\
\text { Mean in years }( \pm S D)\end{array}$ & $\begin{array}{c}50 \\
(12)\end{array}$ & $\begin{array}{c}57 \\
(11)\end{array}$ & -2.417 & $0.025^{*}$ & $\begin{array}{l}0.629 \\
(0.11-1.174)\end{array}$ \\
\hline $\begin{array}{l}\text { Time since NDE } \\
\text { Mean in years }( \pm S D)\end{array}$ & $\begin{array}{c}16 \\
(16)\end{array}$ & $\begin{array}{c}24 \\
(17)\end{array}$ & -2.075 & $0.049^{*}$ & $\begin{array}{l}0.474 \\
(-0.041-0.99)\end{array}$ \\
\hline
\end{tabular}

Notes: * Results are significant. $\mathrm{Cl}=$ Confidence interval. $\mathrm{SD}=$ Standard deviation.

classified as distressing (14\%). The distributions of demographic data of the two emotions-related subsamples follow a normal distribution. Distressing and classical NDErs do not differ in terms of gender and age at NDE. Distressing NDErs however include more suicide survivors, and classical NDErs appear to be older at the time of the interview and to present a longer time elapsed since NDE (see Table 2).

\section{Classification of distressing experiences}

The final classification of all narratives includes 8 inverse, 8 hellish and 1 void (see Table 3 for an example of each subtype of distressing NDE narratives). Additionally, the text analyses revealed that out of the 17 distressing narratives, 6 clearly mention the presence of positive feelings at the beginning of the experience in their written narrative (i.e. peacefulness and/or joy).

\section{Comparison of distressing and classical experiences}

The comparison of distressing and classical NDEs regarding intensity (i.e. Greyson NDE scale total scores) and content (i.e. Greyson NDE scale components) revealed that distressing experiences show lower scores on the affective component $(p<0.001)$. This was supported by Bayesian analyses which showed decisive evidence in favour of a difference between groups (see Table 4). By contrast, distressing and classical accounts do not seem to differ regarding total score as well as on the three other components of the Greyson NDE scale (i.e. cognitive, paranormal and transcendental - see Table 4); Bayesian analyses

Table 3. Text excerpts of written distressing NDE narratives.

\begin{tabular}{|c|c|}
\hline Type & Selected text excerpts translated from French (gender, age at interview) \\
\hline Inverse & $\begin{array}{l}\text { "First, I was sucked into a tunnel. Then, there was a descent into this tunnel. At an incredible speed. Perhaps the speed of light. A speed that does } \\
\text { not last, a flash. It is hard to describe in words, it is very different from what I have experienced in the 'normal' world. This speed gives me the } \\
\text { sensation of 'no time'. In this tunnel, I saw flashes, 'animated' faces of missing people that I had loved (brother, grandfather). The smile of a little } \\
\text { boy murdered when I was five, and lots of people I did not know. I experienced this 'journey' three times. Each time I came back to life. I was } \\
\text { trying to tell the doctor that I was going back into the tunnel, that I would die again, but no sound came out of my mouth. At some point, the } \\
\text { anaesthesiologist said: 'She tries to speak, I do not understand anything'. My mind was talking, screaming, calling for help. But nothing, no } \\
\text { reaction, as if I was in a parallel world. I suffered terribly physically, I was exhausted, I felt abandoned by living beings. I struggled, completely } \\
\text { alone, I did not want to join all these dead beings, although they were welcoming, reassuring. I knew I would die but I was not ready to give in } \\
\text { to the temptation of rest". (Female, } 57 \text { years old) }\end{array}$ \\
\hline Hellish & $\begin{array}{l}\text { "There are more and more entities surrounding me and this dark environment is unbearable. The deafening noise invades the space that becomes } \\
\text { increasingly dark. I would like this noise to stop. I am caught in a whirlwind, the dark grey haze around me is thick, and the smell and sound are } \\
\text { getting more unbearable [...]. And I am beginning to distinguish forms in this incredibly thick fog. Human, bestial, monstrous. I am swimming in } \\
\text { a stinking stench filled with horrible and furtive creatures and I am feeling overwhelmed with pain. It hurts everywhere, no, worse, I am } \\
\text { becoming pain. I understand that my suffering is just beginning. And I am scared. A growing fear, appalling. I would like to close my eyes and } \\
\text { stop hearing and feeling. But it is impossible. My vision is very wide, I see everywhere at once, I see in front of me, above, below and on the } \\
\text { sides; only a small part on the back is not visible. The less I want to hear, see and feel, the more receptive I am. It is terrible, it is like I am } \\
\text { absorbing the pain and suffering of all these beings ... I am extremely lucid, I feel aware like I have never been before. Time no longer exists. I } \\
\text { wish I could escape this place, escape time, but my anguish is such that I cannot move ... as if these beings were holding me back. [...] I } \\
\text { understand that I am between two worlds and that this in-between is none other than Hell". (Female, } 42 \text { years old) }\end{array}$ \\
\hline Void & $\begin{array}{l}\text { "I was in the dark. Time did not exist anymore. I did not have a physical body but the impression of being above it. There was no suffering. I was } \\
\text { nothing. Then, below me, I saw an accident, I saw a girl. She suffered horribly because she was screaming. It hurt to hear her shouting so loud. } \\
\text { Then, everything happened very quickly. This shouting person was me. I tried to get up, I screamed and I fell back. Anxious, I told to myself: 'I am } \\
\text { dead. I do not want to stay in the dark, I want to go to paradise. I have the right to go, I have always done everything properly.' I was floating } \\
\text { into the dark, unaware of what was happening around me. A presence came near me and told me in a loud, clear, authoritarian voice: 'Paradise } \\
\text { does not exist!'. Self-confident, I answered that this is not true and I explained that I have never committed sins. [...] The voice repeated: 'After } \\
\text { death, it is over, there is nothing'. Teachers, priests and sisters taught me that if you never commit mortal sins, you go to heaven. I wanted to go } \\
\text { to heaven. The clear and firm voice told me: 'All those who taught you that lied to you, after death there is nothing!'. [...] The voice disappeared. } \\
\text { No more voice, nothing, it was over. I was desperate, I was crying. Then I fell into an endless darkness at full speed. Always faster. There was } \\
\text { nothing to stop me from falling. I was looking around to grab something. I realized there was nothing. It was total black. I was never going to } \\
\text { stop falling". (Female, } 60 \text { years old) }\end{array}$ \\
\hline
\end{tabular}


Table 4. Score differences between distressing and classical NDEs on the Greyson NDE scale.

\begin{tabular}{|c|c|c|c|c|c|c|c|}
\hline & $\begin{array}{l}\text { Distressing NDEs } \\
\quad(n=17)\end{array}$ & $\begin{array}{l}\text { Classical NDEs } \\
(n=106)\end{array}$ & $W_{s}$ & $p$-Value & $\begin{array}{c}\mathrm{R} \\
\left(\mathrm{Cl}_{95}\right)\end{array}$ & $\mathrm{BF}_{10}$ & $\mathrm{BF}_{01}$ \\
\hline $\begin{array}{l}\text { Affective component } \\
\text { Median(IQR) }\end{array}$ & $\begin{array}{c}2 \\
(1-4)\end{array}$ & $\begin{array}{c}6 \\
(4-7.75)\end{array}$ & 296.5 & $<0.001^{*}$ & $\begin{array}{c}-0.404 \\
(-0.542--0.245)\end{array}$ & 42.276 & 0.135 \\
\hline $\begin{array}{l}\text { Cognitive component } \\
\text { Median(IQR) }\end{array}$ & $\begin{array}{c}3 \\
(2-5)\end{array}$ & $\begin{array}{c}3 \\
(2-6)\end{array}$ & 963.5 & 0.645 & $\begin{array}{c}-0.042 \\
(-0.217-0.136)\end{array}$ & 0.482 & 2.076 \\
\hline $\begin{array}{l}\text { Paranormal component } \\
\text { Median(IQR) }\end{array}$ & $\begin{array}{c}4 \\
(3-6)\end{array}$ & $\begin{array}{c}4 \\
(2-5)\end{array}$ & 1018.5 & 0.385 & $\begin{array}{c}-0.079 \\
(-0.252-0.099)\end{array}$ & -0.303 & 5.701 \\
\hline $\begin{array}{l}\text { Transcendental component } \\
\text { Median(IQR) }\end{array}$ & $\begin{array}{c}4 \\
(3-4)\end{array}$ & $\begin{array}{c}4 \\
(2-6)\end{array}$ & 862.5 & 0.779 & $\begin{array}{c}-0.026 \\
(-0.202-0.151)\end{array}$ & 0.207 & 4.822 \\
\hline $\begin{array}{l}\text { Total score } \\
\text { Mean(SD) }\end{array}$ & $\begin{array}{c}14 \\
(13-16)\end{array}$ & $\begin{array}{c}16 \\
(12-21)\end{array}$ & 667.5 & 0.09 & $\begin{array}{c}-0.155 \\
(-0.323-0.022)\end{array}$ & 0.357 & 2.803 \\
\hline
\end{tabular}

Notes: Results for the components are considered statistically significant at $p<0.01$ after Bonferroni correction. ${ }^{*}$ Results are significant. IQR $=$ Inter-quartile range. $\mathrm{SD}=$ Standard deviation. $\mathrm{BF}_{10}=$ evidence in favour of an effect of the valence (distressing vs. classical) on the scores at the Greyson $\mathrm{NDE} \mathrm{scale}$. $\mathrm{BF}_{01}=$ evidence in favour of a null effect of the valence (distressing vs. classical) on the scores at the Greyson NDE scale.

provided positive evidence for the absence of a difference. The number of distressing NDErs recalling each type of classical NDE feature included in the Greyson NDE scale can be found in Figure 1. Regarding the amount of memory details, the comparison of distressing and classical NDEs revealed a difference regarding emotions felt at the time of the event (i.e. valence) but the other items did not differ; this was supported with Bayesian evidence for the null effect for the majority of items (see Table 5). More specifically, our results indicate stronger evidence for no difference between distressing and classical NDEs in terms of self-reported memory clarity, sensory details, self-referential information, reactivation frequency, and confidence in the memory. This was also the case for emotion-related items, such as the personal importance and the feelings experienced while remembering. To ensure our results are not caused by the effect of confounding variables, we performed the analyses by controlling for age at interview and time since NDE, which led to similar results.

\section{Discussion}

Our main goal was to better document distressing NDEs which remain poorly studied (Bonenfant, 2001; Bush \& Greyson, 1994; Greyson \& Bush, 1992; Irwin \& Bramwell, 1988). This study investigated three major aspects of these experiences: (1) the proportion of distressing NDEs in our sample, (2) their distribution according to the three categories previously established by Greyson and Bush (1992), and (3) the phenomenological and contextual differences existing between the memories of distressing and classical NDEs.

With regard to our first aim, the data suggests that distressing NDEs represent $14 \%$ of our total NDE sample. Earlier studies generally reported percentages ranging from $1 \%$ to 10\% (e.g. Charland-Verville et al., 2014; Greyson \& Bush, 1992). These different proportions can be attributed to the very broad definitions of distressing NDEs, as well as the varying methodologies. By contrast with previous research, we used a rigorous methodology to identify distressing

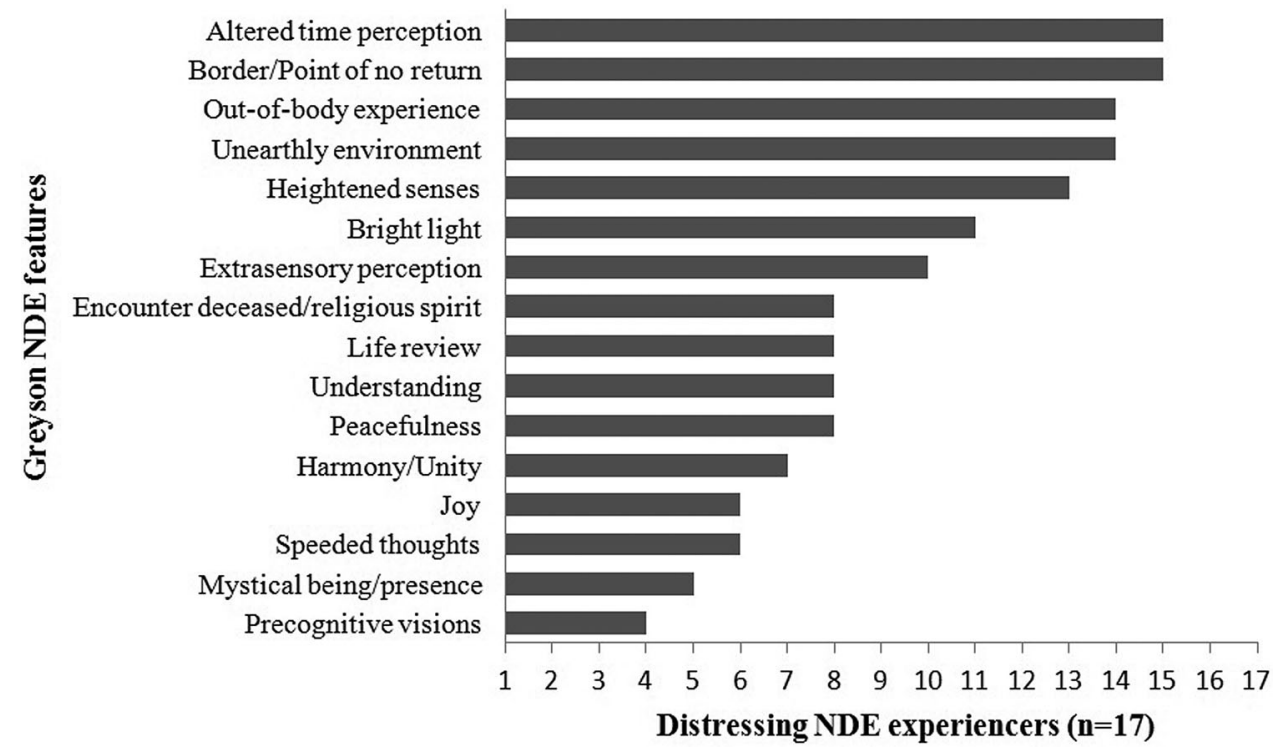

Figure 1. Number of distressing NDErs recalling each NDE feature by decreasing order. 
Table 5. Score differences between distressing and classical NDEs on the MCQ.

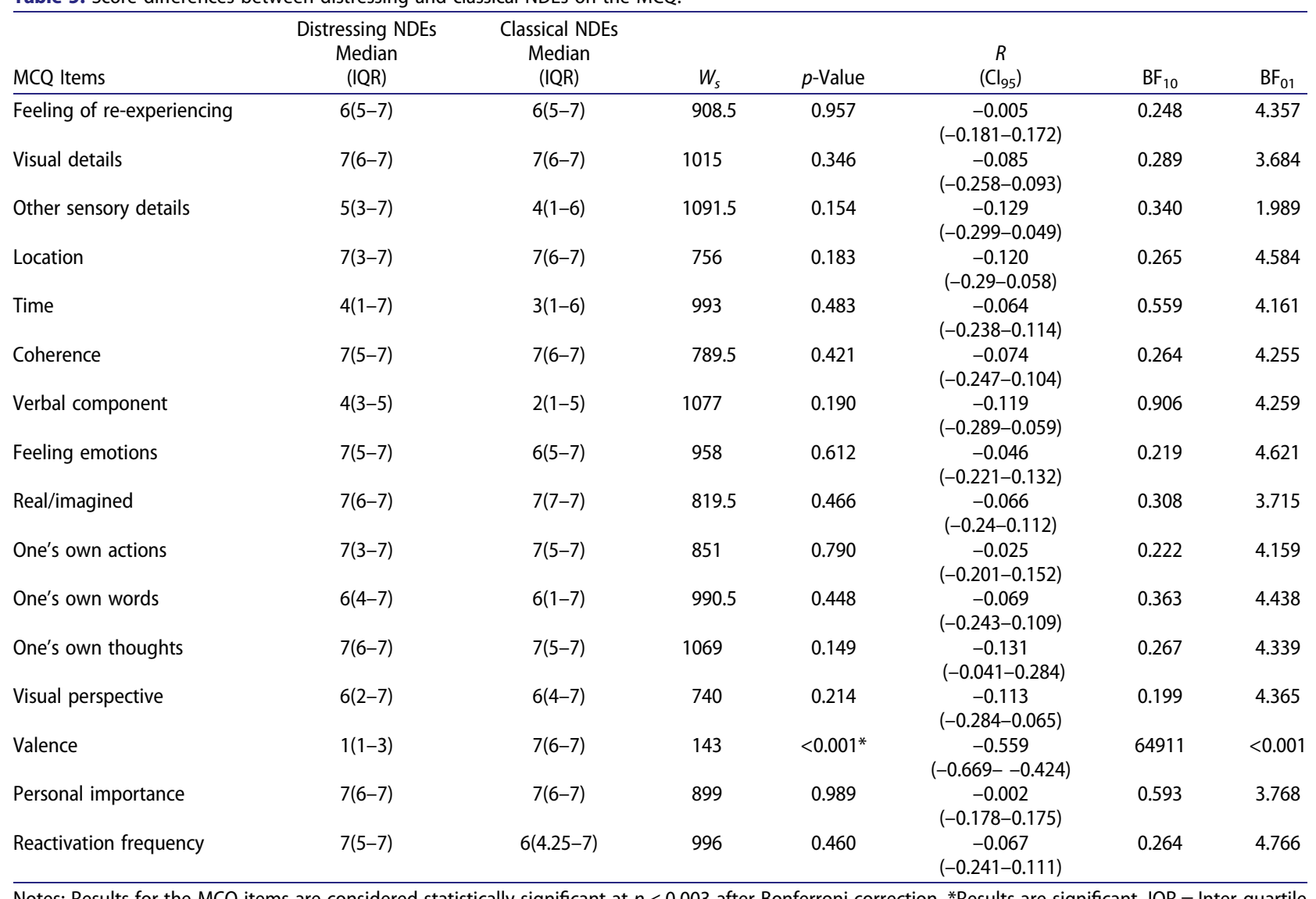

Notes: Results for the MCQ items are considered statistically significant at $p<0.003$ after Bonferroni correction. ${ }^{*}$ Results are significant. IQR $=$ Inter-quartile range. $\mathrm{BF}_{10}=$ evidence in favour of an effect of the valence (distressing vs. classical) on the scores at the $M C Q$. $B F_{01}=e v i d e n c e$ in favour of a null effect of the valence (distressing vs. classical) on the scores at the MCQ.

NDEs (i.e. an item asking NDErs to rate their emotions at the time of the NDE). An additional plausible explanation is that the distressing dimensions of the experience, added to its mystical aspect, could deter people from sharing it. A combination of the aforementioned factors could contribute to the observed discrepancies.

Our second objective was to replicate Greyson and Bush's (1992) classification of distressing NDEs in order to give a more accurate estimate of the number of narratives belonging to each subtype. Indeed, the aforementioned authors did not indicate the number of accounts belonging to each category and what proportion represents their sample of distressing narratives when considering their own database of testimonies. Interestingly, our distribution is not fully in line with the results obtained by Greyson and Bush (i.e. in decreasing order of frequency: the inverse, the void and the hellish NDE; 1992). Indeed, the present sample presents an equal number of inverse and hellish NDE narratives and only one void experience. Although the exact distribution differs, analyses seem to confirm Greyson and Bush's (1992) classification. Rommer (2000) proposed a fourth type composed of a life review during which the NDEr feels negatively judged by a higher power being. We effectively found one distressing narrative that included this feature and could match this category but, in accordance to Bush's (2002) view, it was categorised as hellish. To date, little is known about the resulting consequences of these subtypes of NDEs. Bush and Greyson (1994) however described three possible responses to frightening NDEs: (1) the negative event may be perceived as a warning about unwise behaviours, may lead to a self-analysis and ultimately to a "turn around" in one's life; (2) the NDErs may treat the event as if it did not matter; and (3) the frightening event may result in a difficulty to integrate the experience and in the development of a sense of stigma. As already stated by Bush and Greyson (1994), the literature on post-traumatic growth in NDErs still remains under documented and deserves further research.

Regarding our last aim, distressing and classical NDEs were found to have comparable total scores on the Greyson NDE scale. A detailed analysis revealed that these two types of experiences only differed on the affective subscale. Those findings were expected since three items clearly stipulate the presence of positively connoted emotions. Moreover, the bright light, often described in NDE narratives (Charland-Verville et al., 2014), is known to be often associated with positive emotions such as feelings of happiness, serenity and tranquillity (Cassol et al., 2018; Facco \& Agrillo, 2012). As 
previously stated in Greyson and Bush (1992), scales such as the WCEl (Ring, 1980) or the Greyson NDE scale (Greyson, 1983) seem to place a high value on positive feelings and may therefore be biased and lack sensibility in the identification of negative experiences. It is however interesting to note that, although distressing experiences are significantly less positive, we do not only observe zero values on the affect component of the Greyson NDE scale. By means of a rigorous text analysis, we identified the presence of positive emotions in distressing NDE narratives and highlighted the presence of peacefulness feelings in the beginning of several accounts. Our results therefore seem to corroborate previous studies describing a combination of blissful and frightening elements in some distressing NDEs (e.g. Bonenfant, 2001; Sabom, 1982). Thus, it should also be emphasised that these distressing experiences could be misinterpreted as positive on the unique basis of the Greyson NDE scale. In parallel, results indicate that memories of distressing NDEs are likely to contain as much overall phenomenological details as memories of classical NDEs. A Bayesian analysis revealed no evidence in favour of a difference between the memories of these two types of events, except for the valence. Given that the MCQ allows the assessment of the subjective experience associated with remembering an event (Johnson et al., 1988), this indicates that as compared to memories of classical NDEs, memories of distressing NDEs are associated with a comparable memory clarity, as well as a similar amount of sensory, self-referential and emotional details (i.e. personal importance and feelings experienced while remembering). Moreover, they seem to be retrieved in memory at the same frequency as memories of classical NDEs. Finally, both kinds of NDErs present the same level of confidence in their memory and appear to assign comparable personal importance to the experience. Therefore, our results showed that the memory of distressing NDEs contains a similar level of self-reported phenomenological details as the memory of classical NDEs which are known to be vivid and highly detailed (Thonnard et al., 2013). Finally, we observed a higher proportion of suicidal attempt context in distressing NDErs. Thereupon, we speculate that the negative context surrounding NDEs may have partly influenced their emotional valence. In accordance with neuroscientific and psychological approaches to NDEs (Blackmore, 1996), we hypothesise that their content, in this case the emotional valence, could be influenced by "top-down" processes (i.e. NDErs' knowledge, beliefs and expectations) that are more influential when sensory information is degraded (e.g. altered states of consciousness) or ambiguous.

Overall, we believe that future research should essentially focus on the exploration and understanding of the consequences of these distressing experiences. Past studies focusing on classical NDEs have found that these experiences are self-defining (Cassol, D'Argembeau, Charland-Verville, Laureys, \& Martial, 2019) and have a powerful force of personal change generally reported as very positive (Schwaninger et al., 2002; Van Lommel et al., 2001). Moreover, through their model of sense-making processes and assimilation problems, Bianco, Sambin, and Palmieri (2017) have shown that making sense of a NDE can be a problematic issue, notably because one's previous models about the world may be incongruent with the unusual nature of the NDE-related information. It could therefore be reasonable to think that distressing NDEs might have some powerful negative consequences on NDErs' psychological health. Through a better understanding of such distressing experiences and their consequences, we may become better equipped to target NDErs at high risk of developing long-lasting emotional trauma.

Regarding this study, it should also be noted that the cross-sectional and retrospective design could potentially represent a source of bias in the sense that narratives may have been tainted by widespread descriptions of NDEs in the media and in lay literature. Greyson (2007) however highlighted the consistency of NDE memories over a period of two decades. Additionally, since NDErs voluntarily contacted our team, our sample might suffer from a self-selection bias and the proportion of distressing NDEs might not be genuinely representative. Overall, prospective data collection could constitute a way to address these issues.

\section{Conclusion}

We confirmed Greyson and Bush's (1992) classification which includes inverse, void and hellish NDEs. NDErs report similar ratings for the phenomenological details of distressing and classical NDE memories, which are both highly vivid. This work paves the way for research on the prevalence and consequences of distressing experiences. Frightening NDEs are under documented and require specific attention to be integrated into NDErs' identity.

\section{Acknowledgements}

The authors would like to thank the International Association for NearDeath Studies (IANDS France) and particularly J.-P. Jourdan who helped with near-death experiencers recruitment.

\section{Disclosure statement}

No potential conflict of interest was reported by the authors.

\section{Funding}

The study was further supported by the University and University Hospital of Liege, the Belgian National Funds for Scientific Research (FRSFNRS), the European Union's Horizon 2020 Framework Programme for Research and Innovation under the Specific Grant Agreement No. 785907 (Human Brain Project SGA2), the Luminous project (EUH2020-fetopenga686764), the European Space Agency (ESA) and the Belgian Federal Science Policy Office (BELSPO) in the framework of the PRODEX Programme, the Center-TBI project (FP7-HEALTH602150), the Public Utility Foundation "Université Européenne du 
Travail", "Fondazione Europea di Ricerca Biomedica", the Bial Foundation, the Mind Science Foundation and the European Commission.

\section{References}

Bianco, S., Sambin, M., \& Palmieri, A. (2017). Meaning making after a near-death experience: The relevance of intrapsychic and interpersonal dynamics. Death Studies, 41(9), 562-573. doi:10.1080/ 07481187.2017.1310768

Blackmore, S. J. (1996). Out-of-body experiences. In The encyclopedia of the paranormal (pp. 471-483). Amherst, NY: Prometheus Books.

Bonenfant, R. J. (2001). A child's encounter with the devil: An unusual near-death experience with both blissful and frightening elements. Journal of NearDeath Studies, 20(2), 87-100.

Bush, N. (2002). Afterward: Making meaning after a frightening neardeath experience. Journal of Near-Death Studies, 21(2), 99-133. doi:10.1023/A:1021223618666

Bush, N. E., \& Greyson, B. (1994). Distressing near-death experiences: The basics. Missouri Medicine, 111(6), 486-490.

Cassol, H., D'Argembeau, A., Charland-Verville, V., Laureys, S., \& Martial, C. (2019). Memories of near-death experiences: Are they selfdefining? Neuroscience of Consciousness, 5(1), 1-9.

Cassol, H., Pétré, B., Degrange, S., Martial, C., Charland-Verville, V., Lallier, F., ... Laureys, S. (2018). Qualitative thematic analysis of the phenomenology of near-death experiences. PLOS ONE, 13(2), doi:10.1371/journal.pone.0193001

Charland-Verville, V., Jourdan, J.-P., Thonnard, M., Ledoux, D., Donneau, A.-F., Quertemont, E., \& Laureys, S. (2014). Near-death experiences in non-life-threatening events and coma of different etiologies. Frontiers in Human Neuroscience, 8(203), 1-8.

D'Argembeau, A., \& Van der Linden, M. (2008). Remembering pride and shame: Self-enhancement and the phenomenology of autobiographical memory. Memory (Hove, England), 16(5), 538-547. doi:10. 1080/09658210802010463

Dienes, Z. (2014). Using Bayes to get the most out of non-significant results. Frontiers in Psychology, 5, doi:10.3389/fpsyg.2014.00781

Facco, E., \& Agrillo, C. (2012). Near-death-like experiences without lifethreatening conditions or brain disorders: $\mathrm{A}$ hypothesis from a case report. Frontiers in Psychology, 3(Nov), 1-6. doi:10.3389/fpsyg.2012. 00490

Facco, E., Agrillo, C., \& Greyson, B. (2015). Epistemological implications of near-death experiences and other non-ordinary mental expressions: Moving beyond the concept of altered state of consciousness. Medical Hypotheses, 85(1), 85-93.

Greyson, B. (1983). The near-death experience scale. Construction, reliability, and validity. The Journal of Nervous and Mental Disease, 171(6), 369-375.

Greyson, B. (2007). Consistency of near-death experience accounts over two decades: Are reports embellished over time? Resuscitation, 73(3), 407-411. doi:10.1016/j.resuscitation.2006.10.013

Greyson, B., \& Bush, N. E. (1992). Distressing near-death experiences. Psychiatry, 55, 95-110.

Greyson, B., \& Stevenson, I. (1980). The phenomenology of near-death experiences. American Journal of Psychiatry, 137, 1193-1196.

Groth-Marnat, G., \& Summers, R. (1998). Altered beliefs, Attitudes, and behaviors following near-death experiences. Journal of Humanistic Psychology, 38(3), 110-125. doi:10.1177/00221678980383005

Hou, Y., Huang, Q., Prakash, R., \& Chaudhury, S. (2013). Infrequent near death experiences in severe brain injury survivors - A quantitative and qualitative study. Annals of Indian Academy of Neurology, 16 (1), 75-81. doi:10.4103/0972-2327.107715

Irwin, H. J., \& Bramwell, B. A. (1988). The devil in heaven: A near-death experience with both positive and negative facets. Journal of NearDeath Studies, 7(1), 38-43.

Johnson, M. K., Foley, M. A., Suengas, A. G., \& Raye, C. L. (1988). Phenomenal characteristics of memories for perceived and imagined autobiographical events. Journal of Experimental Psychology, 117(4), 371-376.

Landis, J. R., \& Koch, G. G. (1977). The measurement of observer agreement for categorical data. Biometrics, 33(1), 159-174.

Lange, R., Greyson, B., \& Houran, J. (2004). A Rasch scaling validation of a "core" near-death experience. British Journal of Psychology, 95, 161-177. doi:10.1348/000712604773952403

Lee, M., \& Wagenmakers, E.-J. (2014). Bayesian cognitive modeling: A practical course. Cambridge, UK: Cambridge University Press.

Lindley, J. H., Bryan, S., \& Conley, B. (1981). Near-death experiences in a pacific northwest American population: The evergreen study. Journal of Near-Death Studies, 1, 104-124.

Martial, C., Charland-Verville, V., Cassol, H., Didone, V., Van Der Linden, M., \& Laureys, S. (2017). Intensity and memory characteristics of near-death experiences. Consciousness and Cognition, 56, 120127. doi:10.1016/j.concog.2017.06.018

Moore, L. E., \& Greyson, B. (2017). Characteristics of memories for neardeath experiences. Consciousness and Cognition, 51, 116-124.

Palmieri, A., Calvo, V., Kleinbub, J. R., Meconi, F., Marangoni, M., Barilaro, P.,... Sessa, P. (2014). "Reality" of near-death-experience memories: Evidence from a psychodynamic and electrophysiological integrated study. Frontiers in Human Neuroscience, 8, 429.

Parnia, S., Spearpoint, K., de Vos, G., Fenwick, P., Goldberg, D., Yang, J., ... Schoenfeld, E. R. (2014). AWARE-AWAreness during REsuscitation-A prospective study. Resuscitation, 85(12), 17991805. doi:10.1016/j.resuscitation.2014.09.004

Parnia, S., Waller, D. G., Yeates, R., \& Fenwick, P. (2001). A qualitative and quantitative study of the incidence, features and aetiology of near death experiences in cardiac arrest survivors. Resuscitation, 48(2), 149-156. doi:10.1016/S0300-9572(00)00328-2

Ring, K. (1980). Life at death: A scientific Investigation of the near-death experience. New York, NY: Coward McCann \& Geoghenan.

Ring, K. (1984). Heading toward omega: In search of the meaning of the near-death experience. New York, NY: Coward McCann \& Geoghenan.

Ring, K., \& Franklin, S. (1982). Do suicide survivors report near-death experiences? OMEGA - Journal of Death and Dying, 12(3), 191-208. doi:10.2190/47xb-egmr-9wkp-h3bx

Rommer, B. (2000). Blessing in disguise: Another side of the near-death experience. St. Paul, MN: Llewellyn.

Sabom, M. (1982). Recollections of death: A medical investigation. New York, NY: Simon \& Schuster.

Schwaninger, J., Eisenberg, P. R., Kenneth, B., \& Weiss, A. N. (2002). A prospective analysis of near-death experiences in cardiac arrest Patients. Journal of Near-Death Studies, 20(4), 215-232. doi:10. 1023/a:1015258818660

Thonnard, M., Charland-Verville, V., Brédart, S., Dehon, H., Ledoux, D., Laureys, S., \& Vanhaudenhuyse, A. (2013). Characteristics of neardeath experiences memories as compared to real and Imagined events memories. PLOS ONE, 8(3), 1-5.

Van Lommel, P., Van Wees, R., Meyers, V., \& Elfferich, I. (2001). Neardeath experience in survivors of cardiac arrest: A prospective study in the Netherlands. Lancet, 358(9298), 2039-2045. 